\title{
Low-frequency eddy modulations in the Hawaiian Lee Countercurrent: Observations and connection to the Pacific Decadal Oscillation
}

\author{
Sachiko Yoshida, ${ }^{1}$ Bo Qiu, ${ }^{2}$ and Peter Hacker $^{3}$ \\ Received 17 May 2011; revised 7 September 2011; accepted 3 October 2011; published 8 December 2011. \\ [1] Interannual-to-decadal time scale eddy variability in the Hawaiian Lee Countercurrent \\ (HLCC) band is investigated using the available sea surface height, sea surface temperature, \\ and surface wind stress data sets. In the HLCC band of $17^{\circ} \mathrm{N}-21.7^{\circ} \mathrm{N}$ and $170 \mathrm{E}^{\circ}-160^{\circ} \mathrm{W}$, \\ the prevailing interannual eddy kinetic energy (EKE) signals show enhanced eddy \\ activities in 1993-1998 and 2002-2006, and subpar eddy activities in 1999-2001 and \\ 2007-2009. These interannual EKE signals exhibit little connection to the zonal HLCC \\ velocity changes generated by the dipolar wind stress curl forcing in the immediate lee of \\ the island of Hawaii. Instead, they are highly correlated to the time series of the Pacific \\ Decadal Oscillation (PDO) index. Through a budget analysis for the meridional \\ temperature gradient along the HLCC, we find that during the positive phase of the PDO \\ index, the surface heat flux forcing induces cold (warm) sea surface temperature (SST) \\ anomalies to the north (south) of the HLCC, intensifying the vertical shear between the \\ surface, eastward-flowing HLCC and the subsurface, westward-flowing North Equatorial \\ Current (NEC). This increased vertical shear enhances the baroclinic instability of the \\ HLCC-NEC system and leads to a higher regional EKE level. The opposite processes \\ occur when the PDO switches to a negative phase with the resulting lowered EKE level \\ along the HLCC band. Compared to the surface heat flux forcing, the Ekman flux \\ convergence forcing is found to play a minor role in modifying the meridional SST \\ changes along the HLCC band.
}

Citation: Yoshida, S., B. Qiu, and P. Hacker (2011), Low-frequency eddy modulations in the Hawaiian Lee Countercurrent: Observations and connection to the Pacific Decadal Oscillation, J. Geophys. Res., 116, C12009, doi:10.1029/2011JC007286.

\section{Introduction}

[2] High-quality satellite altimeter observations over the past 17 years have provided us with a unique means to capture the generation of Hawaiian lee eddies. From the altimeter-derived sea surface height anomaly distributions, the Hawaiian lee eddies are known to propagate for long distances while maintaining their strength after being generated to the west of the island of Hawaii. Some of the Hawaiian lee eddy signals are detected in the tide gauge record at Wake Island $\left(19^{\circ} 17^{\prime} \mathrm{N}, 166^{\circ} 37^{\prime} \mathrm{E}\right)$, about $4000 \mathrm{~km}$ west of the island of Hawaii [Mitchum, 1995; Holland and Mitchum, 2001]. Figure 1a shows the distribution of mean eddy kinetic energy (EKE) from the Hawaiian Archipelago to Wake Island derived from the merged altimeter data. The EKE distribution is characterized by a localized maximum

\footnotetext{
${ }^{1}$ Department of Physical Oceanography, Woods Hole Oceanographic Institution, Woods Hole, Massachusetts, USA.

${ }^{2}$ Department of Oceanography, University of Hawai'i at Mānoa, Honolulu, Hawaii, USA.

${ }^{3}$ International Pacific Research Center, University of Hawai'i at Mānoa, Honolulu, Hawaii, USA.

Copyright 2011 by the American Geophysical Union. 0148-0227/11/2011JC007286
}

(EKE $>300 \mathrm{~cm}^{2} / \mathrm{s}^{2}$ ) to the immediate west of the Island of Hawaii and a band of relatively high EKE values (EKE $\sim 200 \mathrm{~cm}^{2} / \mathrm{s}^{2}$ ) along $20^{\circ} \mathrm{N}$. Recent analysis revealed that the localized EKE maximum is induced by the surface wind stress curl forcing that results from the prevailing trade winds interacting with the Hawaii Island orography [Calil et al., 2008; Yoshida et al., 2010]. The wind-forced eddy variability in the immediate lee of the Island of Hawaii has a dominant period of $\sim 60 \mathrm{~d}$ and it is independent of the westward propagating eddy signals along the zonal band of $\sim 20^{\circ} \mathrm{N}$, which have a dominant period of $\sim 100 \mathrm{~d}$. It is these latter propagating eddy signals along $\sim 20^{\circ} \mathrm{N}$ that are the focus of this study.

[3] It is worth noting that the high EKE band along $\sim 20^{\circ} \mathrm{N}$ occupies a region where the mean surface geostrophic flow is directed eastward (see white contours in Figure 1a). Known as the Hawaiian Lee Countercurrent (HLCC) [Qiu et al., 1997; Flament et al., 1998], this eastward mean flow has become a subject of interest from several perspectives. Xie et al. [2001] observed the presence of intense positive and negative wind stress curls confined to the west and southwest of the Island of Hawaii, respectively (see Figure 1b). Using numerical models of various dynamic complexity, they demonstrated that the HLCC is induced by these localized dipolar wind stress curls through the Sverdrup balance and that 

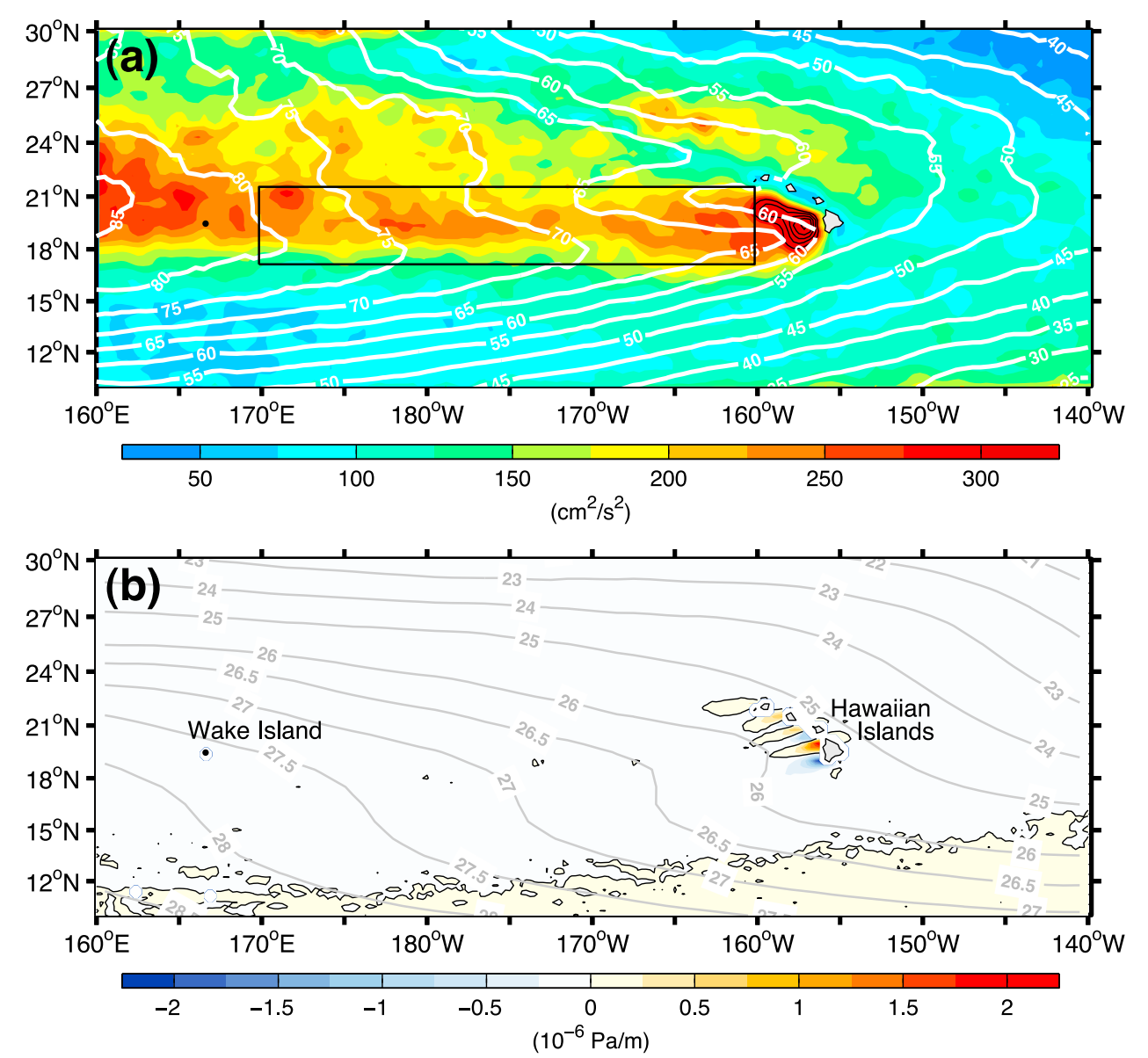

Figure 1. (a) Mean eddy kinetic energy (EKE) around the Hawaiian Islands calculated from the Archiving, Validation, and Interpretation of Satellite Oceanographic merged satellite data from October 1992 to December 2009. Regions where the EKE values exceed $300 \mathrm{~cm}^{2} / \mathrm{s}^{2}$ are indicated by black contours. White contours denote the mean sea surface height fields by Niiler et al. [2003]. Units are in $\mathrm{cm}$. (b) Mean QuikSCAT wind stress curl distribution in the period 1999-2009. Black lines denote the zero mean wind stress curl contours. Gray contour indicates the mean sea surface temperature (SST) field from the NOAA Reynolds SST data set in the period 1993-2009.

the HLCC advects warmer western Pacific surface water eastward and contributes to the positive feedback that sustains the sea surface temperature and surface wind anomalies over a long distance west of the Hawaiian Islands. The role of the HLCC in coupled air-sea interaction is further confirmed recently in numerical modeling studies by Sakamoto et al. [2004] and Sasaki and Nonaka [2006].

[4] Compared to its horizontal features, the vertical structure of the HLCC is less well known because of lack of available observations. Concurrent hydrographic and shipboard Acoustic Doppler Current Profiler (ADCP) surveys reveal that the HLCC exists in the upper $200 \mathrm{~m}$ layer along $165^{\circ} \mathrm{W}$ and it tends to deepen toward the west [Qiu and Durland, 2002]. Figure 2 shows the zonally averaged latitude-depth sections of the time-mean temperature and zonal geostrophic velocity calculated from the Argo ensemble mean data set downloaded from the Asia-Pacific DataResearch Center (http://apdrc.soest.hawaii.edu/). Here, the time-mean temperature section is constructed from the available temperature-salinity profiles of Argo floats from 2005 through 2009, and the zonal geostrophic velocity is computed with the use of a reference level at $2000 \mathrm{dbar}$ from dynamic calculation. The time-mean HLCC exists as a relatively shallow and weak eastward current within a narrow latitudinal width from $18.5^{\circ} \mathrm{N}$ to $20.5^{\circ} \mathrm{N}$ and is embedded in the large-scale, wind-driven, westward-flowing North Equatorial Current (NEC) between $8^{\circ} \mathrm{N}$ to $30^{\circ} \mathrm{N}$. The HLCC has a surface intensified velocity at $0.05 \mathrm{~m} / \mathrm{s}$ and extends to about $200 \mathrm{~m}$, where the mean velocity becomes zero. In Figure 2, another eastward-flowing, surface flow appears north of $23^{\circ} \mathrm{N}$ and it corresponds to the North Pacific Subtropical Countercurrent (STCC) [Uda and Hasunuma, 1969; Hasunuma and Yoshida, 1978].

[5] Overlying the westward-flowing NEC, the eddy variability associated with the HLCC shares a commonality with that associated with the STCC. On the seasonal time scale, Kobashi and Kawamura [2002] point out that these two countercurrents become baroclinically more unstable during late fall to winter as a result of stronger vertical velocity shear and weaker stratification. They also report that the spatial scales and growth rates of the most unstable waves have similar values at 300-400 km and 2-3 months between these two countercurrents. More recently, Sasaki et al. [2010] show that the seasonal change in the HLCC intensity is 


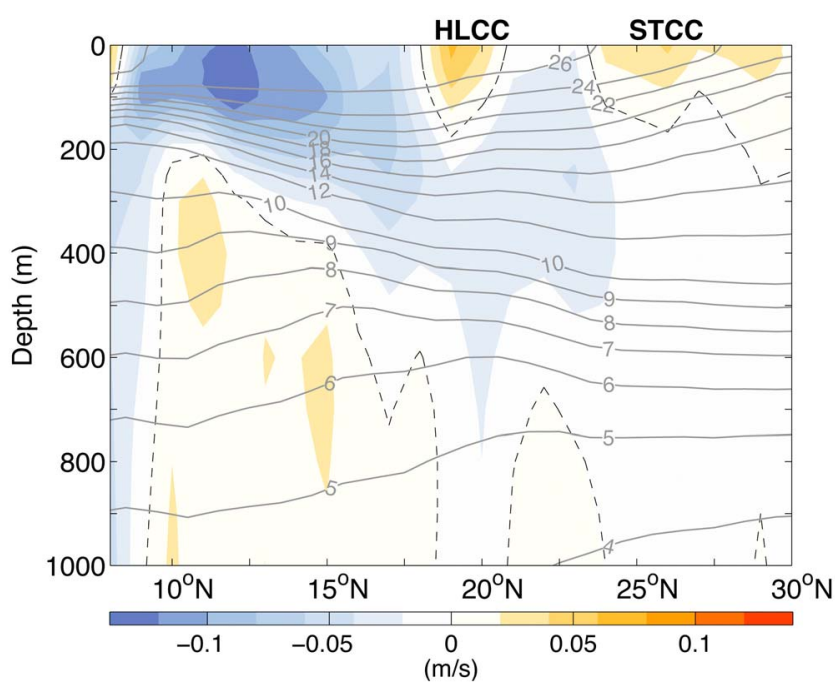

Figure 2. Latitude-depth sections of zonal geostrophic velocity (color shading) and temperature (gray solid contours) of $170^{\circ} \mathrm{E}-160^{\circ} \mathrm{W}$ for the Argo 2005 to 2009 ensemble mean data set. Dashed lines denote the zero velocity contours.

largely controlled by sea surface height signals south of the HLCC generated by wind stress curl anomalies southwest of the Island of Hawaii.

[6] In comparison with the seasonal variations of the HLCC, our knowledge of the interannual and longer time scale variability of the HLCC is more fragmentary. For the interannual variability in STCC, Qiu and Chen [2010] find an enhanced vertical shear between the STCC and NEC in years of increased eddy kinetic energy level from the analysis of repeat hydrographic data along $137^{\circ} \mathrm{E}$. They attribute its cause to the surface Ekman temperature gradient convergence within the STCC band associated with the Western Pacific pattern. For the interannual variability in the strength of the HLCC, a recent ocean general circulation model (OGCM) study by Sasaki et al. [2010] suggested the possibility of the connection to the time-varying intrusion of lowpotential vorticity (PV) water from north of the HLCC. The low-PV water identified by Sasaki et al. [2010] resides on the $26.0 \sigma_{\theta}$ (or, equivalently, $12^{\circ} \mathrm{C}$ ) surface. As shown in Figure 2, this isopycnal surface exists at the $300 \mathrm{~m}$ depth and is much deeper than the body of the HLCC. The effectiveness of time-varying PV values on this isopycnal surface in affecting the strength of the overlying HLCC is an issue that requires further examination.

[7] In the present study, we examine the HLCC variability on the interannual and longer time scales by analyzing available data of sea surface height, sea surface temperature, and surface wind stresses. Our first objective is to describe the interannual and longer time scale eddy variability along the HLCC band. Since baroclinic instability is the main cause for eddy variability, it is possible to infer the intensity changes of the HLCC from the observed changes in the HLCC's eddy kinetic energy level. The second objective of this study is to explore the forcing mechanisms responsible for the inferred HLCC intensity variability. Both forcings due to the wind stress curl variability in the lee of the Island of Hawaii, and due to the Ekman flux divergence and differential heat flux forcing overlying the HLCC, are investigated.

\section{Hawaiian Lee Countercurrent Eddy Kinetic Energy Interannual Variability}

[8] To explore the eddy variability along the HLCC band, we use the satellite altimetry sea surface height (SSH) anomaly data set provided by the Collecte Localization Satellites Space Oceanographic Division of Toulouse, France (http://www.aviso.oceanobs.com/). This is a merged data set with TOPEX/Poseidon, European Remote Sensing Satellite, Geosat Follow-On, Jason 1, and Jason 2 along-track SSH measurements. It covers the period from October 1992 to December 2009 with a weekly interval and a one-third degree by one-third degree spatial resolution.

[9] Figure 3a shows the time series of EKE averaged in the zonal band of $17.0^{\circ} \mathrm{N}-21.7^{\circ} \mathrm{N}, 170.0^{\circ} \mathrm{E}-160.0^{\circ} \mathrm{W}$ (the black boxed area shown in Figure 1a). The western edge of the band is selected to differentiate the HLCC variability from that of the southern STCC which tends to veer northeastward east of $160^{\circ} \mathrm{E}$ [Kobashi et al., 2006]. The eastern edge is chosen to exclude the influence from the windgenerated $60 \mathrm{~d}$ eddy variability in the immediate lee of the Island of Hawaii [Yoshida et al., 2010]. The EKE is estimated from the gridded SSH anomaly data by assuming geostrophy. Despite the strong interannual variability, a clear annual cycle in EKE is present. Specifically, there is a tendency for the EKE level drop to a minimum from fall to winter and to rebound in spring. This is consistent with the result of Kobashi and Kawamura [2002] that the HLCC is baroclinically more unstable during late fall to winter and that it takes 2 to 3 months for the EKE level to intensify in spring. The seasonal EKE signal and its relation with the forcing are discussed in section 4 .

[10] Figure 3b shows the seasonally averaged EKE time series after removing the annual running mean value. As is also evident in Figure 3a, the EKE level shifts between the
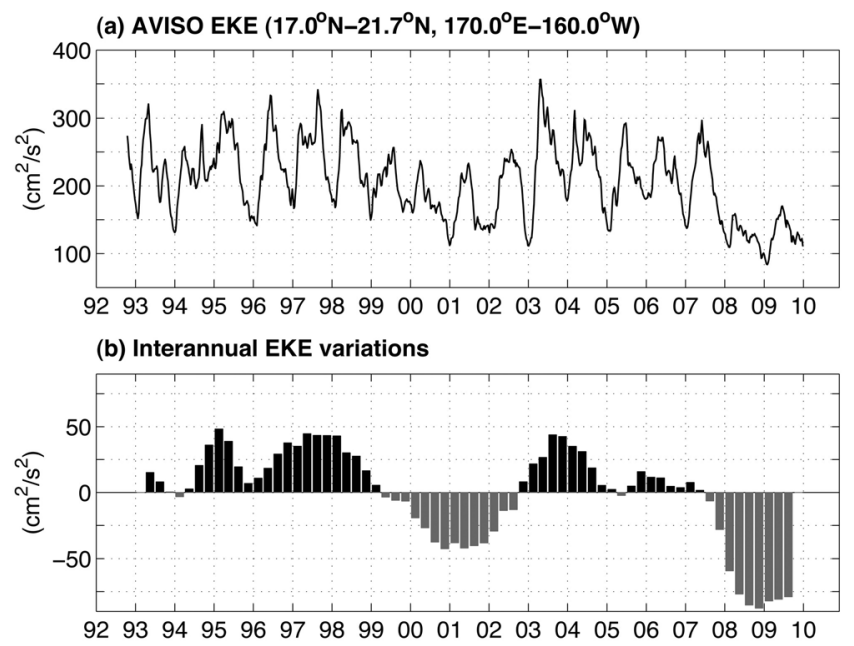

Figure 3. (a) EKE time series in the Hawaiian Lee Countercurrent (HLCC) region of $17.0^{\circ} \mathrm{N}-21.7^{\circ} \mathrm{N}, 170.0^{\circ} \mathrm{E}-$ $160.0^{\circ} \mathrm{W}$. (b) Interannual changes of the EKE time series after a 1 year running mean is applied to the original weekly time series shown Figure 3a. 

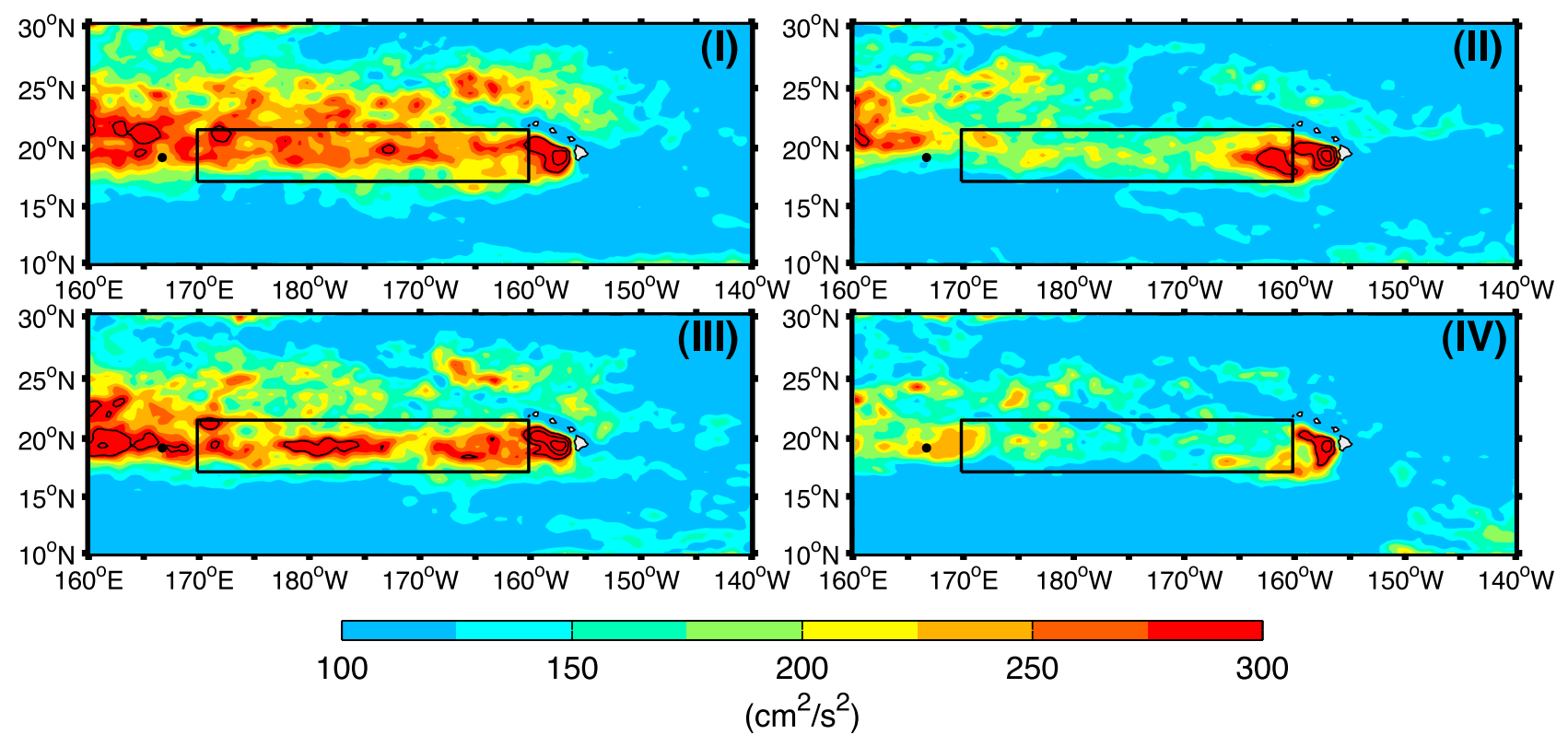

Figure 4. Horizontal maps of eddy kinetic energy averaged in periods I (1993-1998), II (1999-2002), III (2003-2006), and IV (2007-2009). Regions where the EKE values exceed $300 \mathrm{~cm}^{2} / \mathrm{s}^{2}$ are indicated by black contours.

high periods in 1993-1998 and 2003-2006, and relatively weak periods in 1999-2002 and 2007-2009. Since the dominant wave period of the eddy variability throughout 1992-2009 appears at 90 to $100 \mathrm{~d}$ by spectrum analysis (see Figure 5 of Yoshida et al. [2010]), the EKE changes shown in Figure $3 \mathrm{~b}$ reflect the interannual amplitude modulations of the 90-100 d signals within the HLCC band. In the following analysis, we will refer to years 1993-1998, 1999-2002, 2003-2006, and 2007-2009 as periods I, II, III and IV, respectively.

[11] To investigate the spatial EKE distributions among the four periods, we present in Figure 4 the horizontal EKE maps averaged in each period from I to IV. Compared with the low EKE periods II and IV, the eddy variability in the lee of the Hawaiian Islands is observed to extend more coherently to the west in the high EKE periods I and III. The EKE values averaged within the black box shown in Figure 4 are $232.9 \mathrm{~cm}^{2} / \mathrm{s}^{2}, 185.36 \mathrm{~cm}^{2} / \mathrm{s}^{2}, 225.62 \mathrm{~cm}^{2} / \mathrm{s}^{2}$ and $154.25 \mathrm{~cm}^{2} / \mathrm{s}^{2}$ for the periods I, II, III and IV, respectively. Rather than confined to the HLCC band, the EKE level in the surrounding areas have also changed in these four periods. The EKE level to the north of the Islands chain and west of the HLCC band has intensified during periods I and III, suggesting the forcing is likely to be large scale [Qiu and Chen, 2010; Chen and Qiu, 2010].

[12] Figure 5, showing the longitude-time EKE section averaged between $17.0^{\circ} \mathrm{N}$ and $21.7^{\circ} \mathrm{N}$, provides an alternative view of the interannually modulating EKE signals. The EKE signals between $156^{\circ} \mathrm{W}$ and $160^{\circ} \mathrm{W}$ west of the Island of Hawaii represent the $60 \mathrm{~d}$ signals generated by local wind stress curl forcing and they exhibit no distinct interannual changes [Yoshida et al., 2010]. The interannually modulating $100 \mathrm{~d}$ signals of our interest exist to the west of $160^{\circ} \mathrm{W}$ and are distinguished from the wind-driven $60 \mathrm{~d}$ signals. During periods I and III, enhanced 90-100 d eddy signals can be seen to propagate westward beyond the dateline, and some are able to reach the Wake Island $\left(19^{\circ} 17^{\prime} \mathrm{N}, 166^{\circ} 37^{\prime} \mathrm{E}\right)$ with a speed of about $6.8 \mathrm{~cm} / \mathrm{s}$. This is close to the speed, 7$8 \mathrm{~cm} / \mathrm{s}$ at this latitude, expected for first mode baroclinic Rossby waves, and eddies formed in the lee of the Island of Hawaii are known to travel for a long distance [Chelton and Schlax, 1996; Mitchum, 1995]. Compared to the persistent EKE signals during periods I and III, fewer eddy signals are generated during periods II and IV.

\section{Dipole Wind Forcing Variations}

[13] Interaction by the persistent northeasterly trade wind with the island orography plays an important role in the lee region of the Hawaiian Islands. The wind stress curl anomaly produced by the island of Hawaii has been shown both observationally and numerically to be the cause for generating the mean HLCC [Xie et al., 2001; Sakamoto et al., 2004]. To clarify the cause underlying the interannual EKE modulations observed in the HLCC, it is natural to ask to what extent the wind forcing field in the lee of Island of Hawaii has varied over the past 18 years.

[14] To estimate the HLCC zonal velocity changes associated with the low-frequency wind forcing, we consider the continuity equation $\partial u / \partial x+\partial v / \partial y=0$ with an assumption of small vertical motion. In the western vicinity of the island, we can write the continuity equation in the following discretized form:

$$
\frac{u_{i+1}-u_{i}}{L_{x}}+\frac{v_{j+1}-v_{j}}{L_{y}}=0,
$$

where $u_{i+1}$ is the zonal velocity at the eastern boundary and is zero where the eastern boundary is chosen at the Island of Hawaii. $u_{i}$ is the zonal velocity at a distance $L_{x}$ west of the island; it represents the HLCC of our interest. $v_{j+1}$ and $v_{j}$ are 


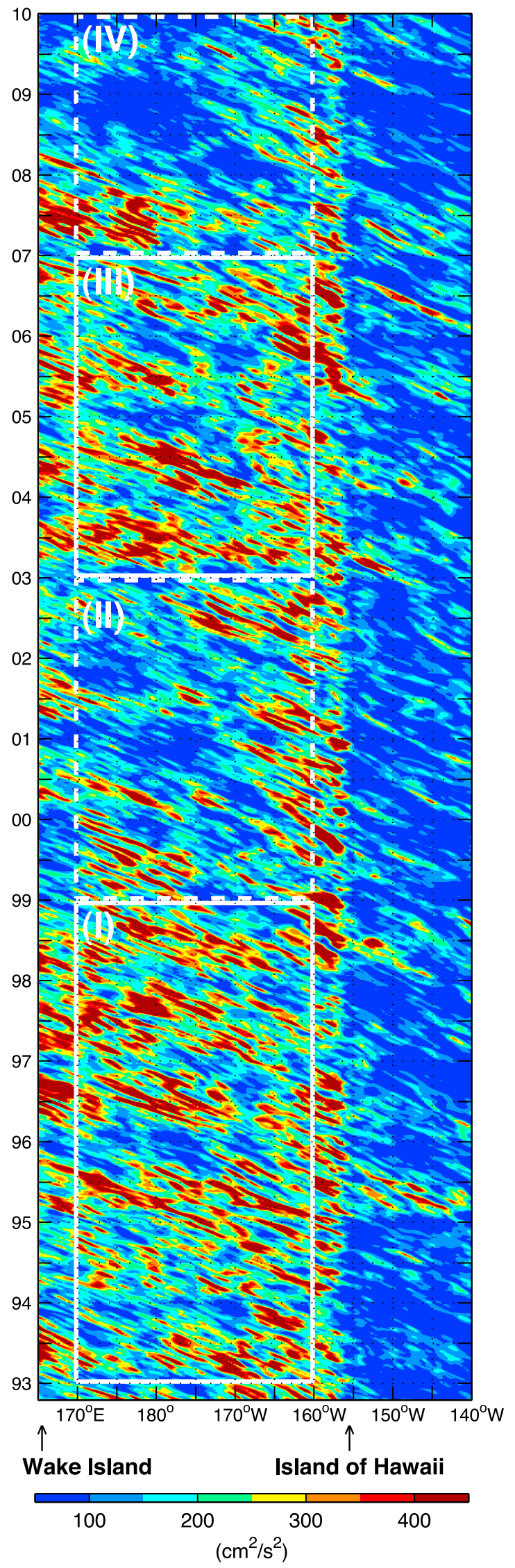

the meridional velocities at the latitudes of the island's northern and southern tips, which are separated by $L_{y}$. Assuming the Sverdrup balance between the meridional velocity and the wind stress curl forcing, we can evaluate the HLCC by

$$
u_{i}=\frac{L_{x}}{L_{y}} \frac{1}{\rho_{0} \beta H_{0}}\left(\nabla \times \tau_{j+1}-\nabla \times \tau_{j}\right),
$$

where $\rho_{0}$ is the reference density, $\beta$ is the meridional gradient of the Coriolis parameter, $H_{0}$ is the depth of the winddriven HLCC, $\tau_{j+1}$ and $\tau_{j}$ are the surface wind stress anomaly vectors at the latitudes of the island's northern and southern tips, respectively. To estimate $u_{i}$ from equation (2), we use two wind stress data sets. The first one is the monthly wind stress data from a new operational ocean analysis/ reanalysis system (ORA-S3) implemented at European Centre for Medium-Range Weather Forecasts (ECMWF) [Balmaseda et al., 2008]. This wind stress data set has a $1^{\circ} \times 1^{\circ}$ spatial resolution and is insufficient to resolve small-scale wind stress structures. The wind stress curl of this data set only produces one positive and negative pair of anomalies west of the Hawaiian Islands as shown in Figure 6a. The gray line in Figure 6c shows the time series of $\nabla \times \tau_{j+1}-\nabla \times \tau_{j}$ anomalies between the areas labeled $\mathrm{N}$ and $\mathrm{S}$ in Figure 6a. As indicated by its low-pass filtered time series shown by the thick black line, the wind stress curl difference has persistent negative and positive anomalies during the period 1995 to early 1998 and late 1998 to 2001 , respectively. Since the wind stress curl in the lee of the Island of Hawaii is the dominant forcing for the mean and seasonally varying HLCC, these anomalies suggest that the HLCC should be less (more) intense and the EKE level lower (higher) in 1995 to early 1998 (late 1998-2001). The EKE level changes observed in 1995-2001, as shown in Figure 3b, had opposite signs. Similarly, Figure 6c shows no significant interannual changes in $\nabla \times \tau_{j+1}-\nabla \times \tau_{j}$ after 2002, whereas the observed EKE had a clear sign change in late 2007. In short, the mismatch between the time series of Figure $6 \mathrm{c}$ and Figure $3 \mathrm{~b}$ implies that the interannual EKE changes in HLCC are not controlled by the dipolestructured wind forcing in the lee of the Island of Hawaii.

[15] Since the ECMWF wind does not resolve the individual anomaly pairs west of each island, we also calculate the wind stress curl anomaly difference $\nabla \times \tau_{j+1}-\nabla \times \tau_{j}$ from the high-resolution QuikSCAT satellite data as a consistency check. The QuikSCAT monthly data cover from August 1999 until November 2009 and have a one-fourth degree horizontal resolution. Figure 6d shows the QuikSCAT wind stress curl anomaly difference $\nabla \times \tau_{j+1}-\nabla \times \tau_{j}$ between the areas labeled $\mathrm{N}$ and $\mathrm{S}$ in Figure 6b. Although the labeled areas in Figures $6 \mathrm{a}$ and $6 \mathrm{~b}$ are geographically different, the time series in Figure 6d shows the interannual variations similar to those in the ECMWF wind data during their overlapping period. The two time series in Figures $6 \mathrm{c}$

Figure 5. Longitude-time section of eddy kinetic energy. The period of intensified and relatively low EKE levels at periods I (1993-1998), II (1999-2002), III (2003-2006), and IV (2007-2009) are shown with white solid and broken lines, respectively. 

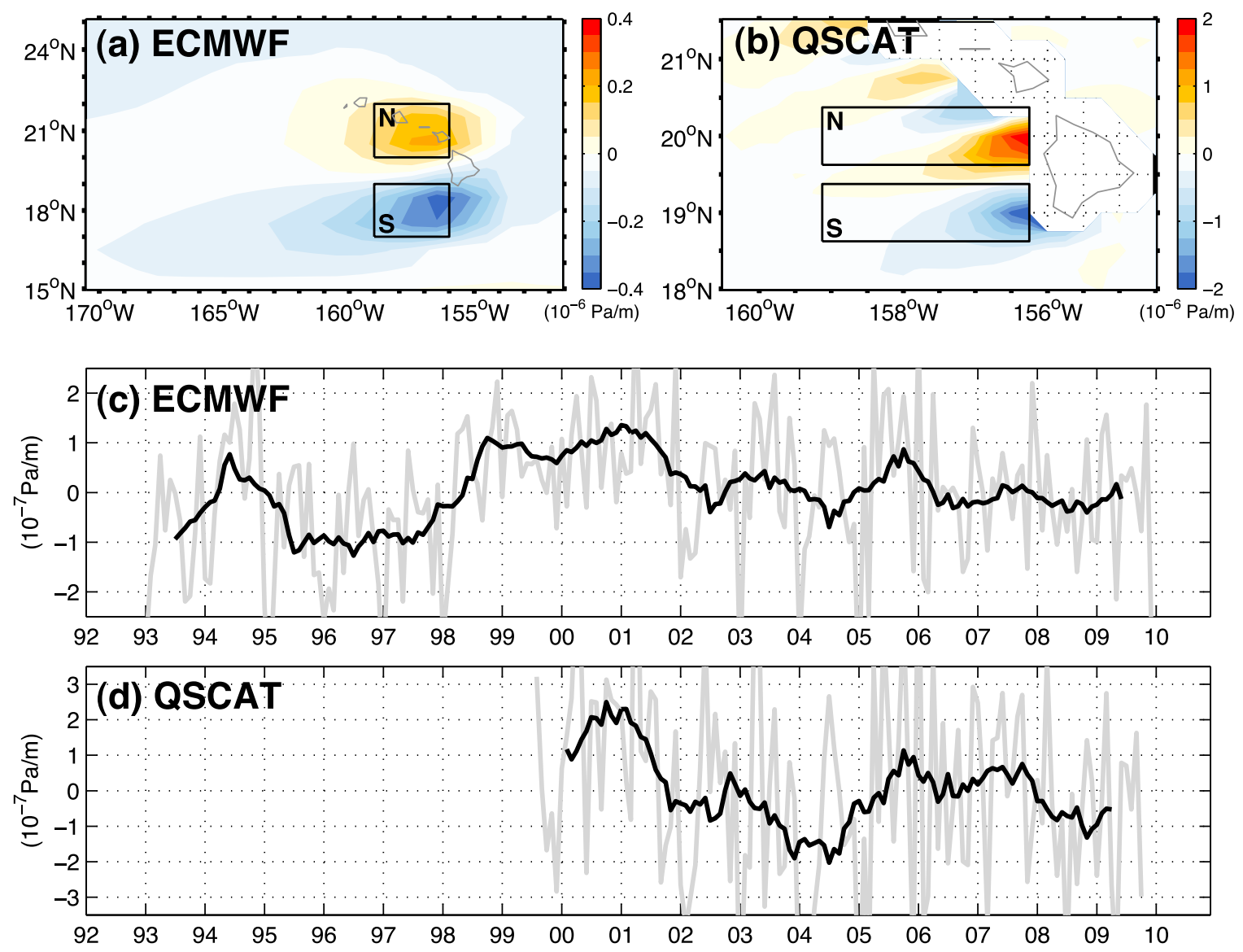

Figure 6. Mean wind stress curl distribution from (a) European Centre for Medium-Range Weather Forecasts (ECMWF) and (b) QuikSCAT in the period January 1993 to December 2009 and August 1999 to November 2009, respectively. (c) Gray curve indicates ECMWF wind anomaly differences between the areas labeled $\mathrm{N}$ and $\mathrm{S}$ in Figure 6a. Black curve indicates interannual changes of the wind anomaly differences after 13 month running mean filter is applied to the original monthly time series.

(d) Same as Figure 6c but from the QuikSCAT wind stress anomaly differences in Figure 6b.

and $6 \mathrm{~d}$ are well correlated with the linear correlation coefficient at 0.81. As the ECMWF wind stress curl data are available for a longer period of time while capturing the important spatial pattern in the lee of the Island of Hawaii, we will use the ECMWF data for the subsequent analysis.

\section{Ekman Convergence Dynamics and Heat Flux Forcing}

[16] In the analysis of section 3, there is no evidence to support our first hypothesis that the interannual EKE changes in HLCC are governed by the localized wind stress curl forcing in the lee of the Island of Hawaii. In this section, we adopt a different hypothesis and examine the extent to which the interannual EKE changes in HLCC can be explained by the regional surface wind stress and heat flux forcing over the HLCC band (see the black box in Figure 1a). Following Qiu and Chen [2010], the vertical shear in the zonal geostrophic velocity $\left(U_{g}\right)$ is related to the meridional temperature $(T)$ gradient through the thermal wind balance:

$$
f \frac{\partial U_{g}}{\partial z}=-\alpha g \frac{\partial T}{\partial y},
$$

where $f$ is the Coriolis parameter, $g$ is the gravity constant, and $\alpha$ is the thermal expansion coefficient. Using equation (3), investigation of the interannual EKE changes in the HLCC becomes equivalent to examining the regional meridional temperature gradient changes in the surface HLCC layer. Following Figure 2, we set the surface HLCC layer thickness $H_{0}=150 \mathrm{~m}$. The three-dimensional heat balance equation for the surface HLCC layer is given by

$$
\frac{\partial T}{\partial t}=-u \frac{\partial T}{\partial x}-v \frac{\partial T}{\partial y}-w \frac{\partial T}{\partial z}+\frac{Q_{n e t}}{\rho_{0} c_{p} H_{0}},
$$

where $Q_{n e t}$ is the surface net heat flux (defined as positive from atmosphere to ocean), $\rho_{0}$ is the reference density, and $c_{p}$ is the specific heat of seawater at constant pressure. By neglecting the vertical advection term in equation (4) and by denoting $G \equiv-\partial T / \partial y$ following Nakamura and Kazmin [2003], we can transform equation (4) to the following frontogenesis equation:

$$
\frac{\partial G}{\partial t}=\frac{\partial}{\partial y}\left(u \frac{\partial T}{\partial x}\right)-\frac{\partial}{\partial y}(v G)-\frac{\partial}{\partial y}\left(\frac{Q_{n e t}}{\rho_{0} c_{p} H_{0}}\right) .
$$



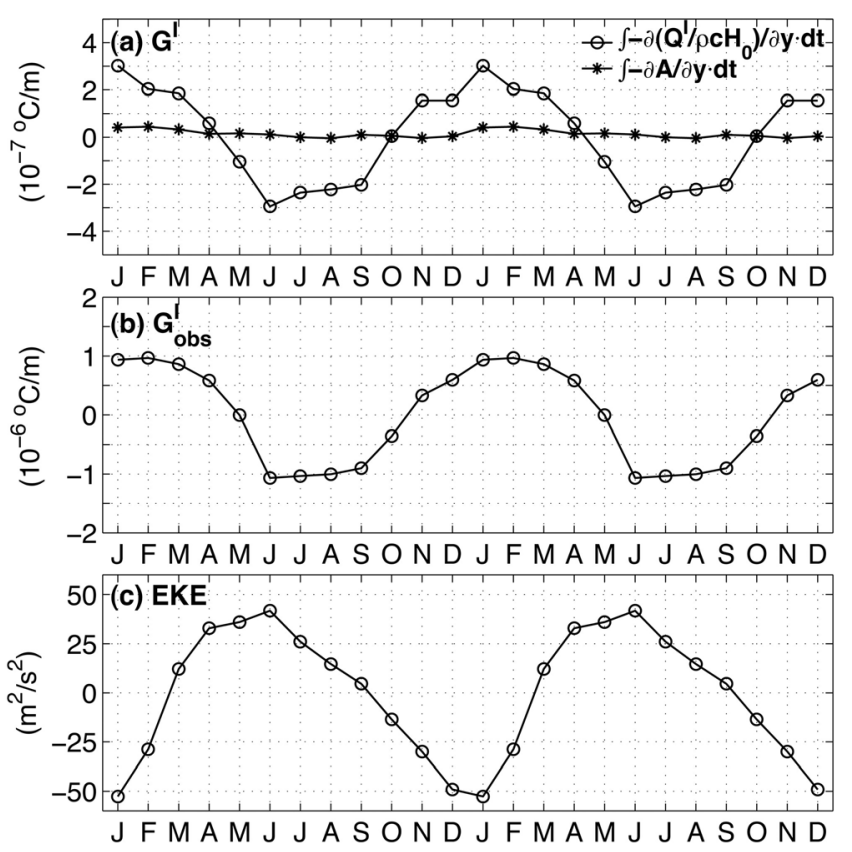

Figure 7. Seasonal variation of (a) the differential surface heat flux forcing (circle) and the Ekman flux convergence forcing (star) terms, (b) $G_{o b s}^{\prime}$, and (c) EKE averaged in the HLCC region.

Since the HLCC is a zonally aligned current, the meridional velocity $v$ in equation (5) is determined largely by the Ekman flow in the surface layer: $v_{E K}=-\tau^{x} / \rho_{0} f H_{0}$. Using Reynolds' decomposition and focusing on the time-varying component $G^{\prime}$, the zonal advection term in equation (5) is negligible compared to the meridional component. We can rewrite the frontogenesis equation as

$$
\frac{\partial G^{\prime}}{\partial t}=-\frac{\partial A}{\partial y}-\frac{\partial}{\partial y}\left(\frac{Q_{n e t}^{\prime}}{\rho_{0} c_{p} H_{0}}\right)
$$

where $G=\bar{G}+G^{\prime}, v_{E K}=\bar{v}_{E K}+v_{E K}^{\prime}, Q_{n e t}=\bar{Q}_{n e t}+Q_{n e t}^{\prime}$, $A=v_{E K}^{\prime} G^{\prime}+v_{E K}^{\prime} \bar{G}+\bar{v}_{E K} G^{\prime}$ and primed (overbar) variables denote time-varying anomalies (time-mean values). Physically, equation (6) indicates that the temporal changes in $G^{\prime}$ can result from the convergence of Ekman flux and the differential surface heat flux forcing in the $y$ direction. To evaluate the two terms on the right-hand side of equation (6), we use the $1^{\circ} \times 1^{\circ}$ monthly zonal wind stress $\tau^{x}$ and surface net heat flux $Q_{n e t}$ data from ECMWF ORA-S3. By integrating equation (6) in time, we evaluate the two components of $G^{\prime}$ in equation (7) and compare this modeled $G^{\prime}$ time series against the observed $G_{o b s}^{\prime}$ time series based on the $1^{\circ} \times 1^{\circ}$ monthly sea surface temperature anomaly (SSTA) data compiled by NOAA [Reynolds et al., 2002] using equation (8):

$$
\begin{gathered}
G^{\prime}=-\int \frac{\partial A}{\partial y} d t-\int \frac{\partial}{\partial y}\left(\frac{Q_{n e t}^{\prime}}{\rho_{0} c_{p} H_{0}}\right) d t, \\
G_{o b s}^{\prime}=-\frac{\partial(S S T A)}{\partial y} .
\end{gathered}
$$

For clarity, the comparisons are conducted below on the seasonal and interannual time scales separately.

\subsection{Seasonal Variation}

[17] Seasonal variations in the integrated Ekman flux convergence and differential heat flux terms are shown in Figure 7a. The seasonal signals of $G^{\prime}$ and $G_{o b s}^{\prime}$ are calculated by forming the monthly climatology of the past 17 years (1993-2009). Between the two terms of $G^{\prime}$, the integrated differential heat flux forcing term is clearly dominant. The $G^{\prime}$ signal induced by the integrated differential heat flux forcing has a well-defined seasonal cycle with a maximum in winter (January) and a minimum in summer (June). This seasonal cycle agrees favorably in phase with $G_{o b s}^{\prime}$ shown in Figure $7 \mathrm{~b}$. Because of the strong seasonal temperature variability within the upper $150 \mathrm{~m}$ layer, $G_{o b s}^{\prime}$ has an amplitude about 3 times as large as that of the differential heat flux forcing term. The $G_{o b s}^{\prime}$ calculated from the Argo temperature anomaly averaged over the surface $150 \mathrm{~m}$ layer fits reasonably well with the amplitude range of the differential heat flux forcing (not shown). For comparison, we plot in Figure 7c the seasonal variations of EKE averaged in the HLCC band (recall Figure $3 b$ ). The seasonal EKE level peaks in spring to early summer (April to June) and drops to a minimum in winter (November to January). This $3 \sim 5$ months delay by the EKE maximum behind the $G^{\prime}$ maximum is consistent with the time that is required by the baroclinic instability to fully grow [Kobashi and Kawamura, 2002].

\subsection{Interannual Modulation}

[18] Figures $8 \mathrm{a}, 8 \mathrm{~b}$ and $8 \mathrm{c}$ show the interannual modulations of the differential heat flux forcing, the Ekman flux convergence forcing and the $G_{o b s}^{\prime}$ time series, respectively. The gray thick curves in Figures $8 \mathrm{a}$ and $8 \mathrm{~b}$ denote the interannual signals after a 13 month running mean average is applied to the original monthly time series. Like the seasonal signals, the Ekman flux convergence forcing term (Figure 8b) has relatively small amplitude in comparison with the differential heat flux forcing term (Figure 8a) and differs from the $G_{o b s}^{\prime}$ time series both in time scales and phases. The $G^{\prime}$ signals induced by the differential heat flux forcing term are positive during 1994 to 1997 and 2001 to mid-2005, and negative during 1998 to 2000 and mid-2005 to early 2009 . These interannual $G^{\prime}$ signals agree reasonably well with the interannual $G_{o b s}^{\prime}$ signals in Figure 8c both in amplitude and in phase.

[19] Notice that the interannually varying $G_{o b s}^{\prime}$ (and the differential heat flux forcing) signals match well with the interannually varying EKE signals shown in Figure 8d. A correlation analysis reveals that the two time series have a maximum correlation coefficient exceeding 0.8 when $G_{o b s}^{\prime}$ leads EKE by 8-10 months (Figure 9). Since the interannually varying $G_{o b s}^{\prime}$ signals are related to the interannually varying HLCC shear according to equation (3), it is possible to conclude that the interannually varying EKE signals observed in the HLCC band are due to the differential heat flux forcing and its induced changes in HLCC shear. The 8 months lead identified in Figure 9 is likely the time required for the HLCC-NEC shear to adjust to the timevarying differential heat flux forcing, plus the time for the 

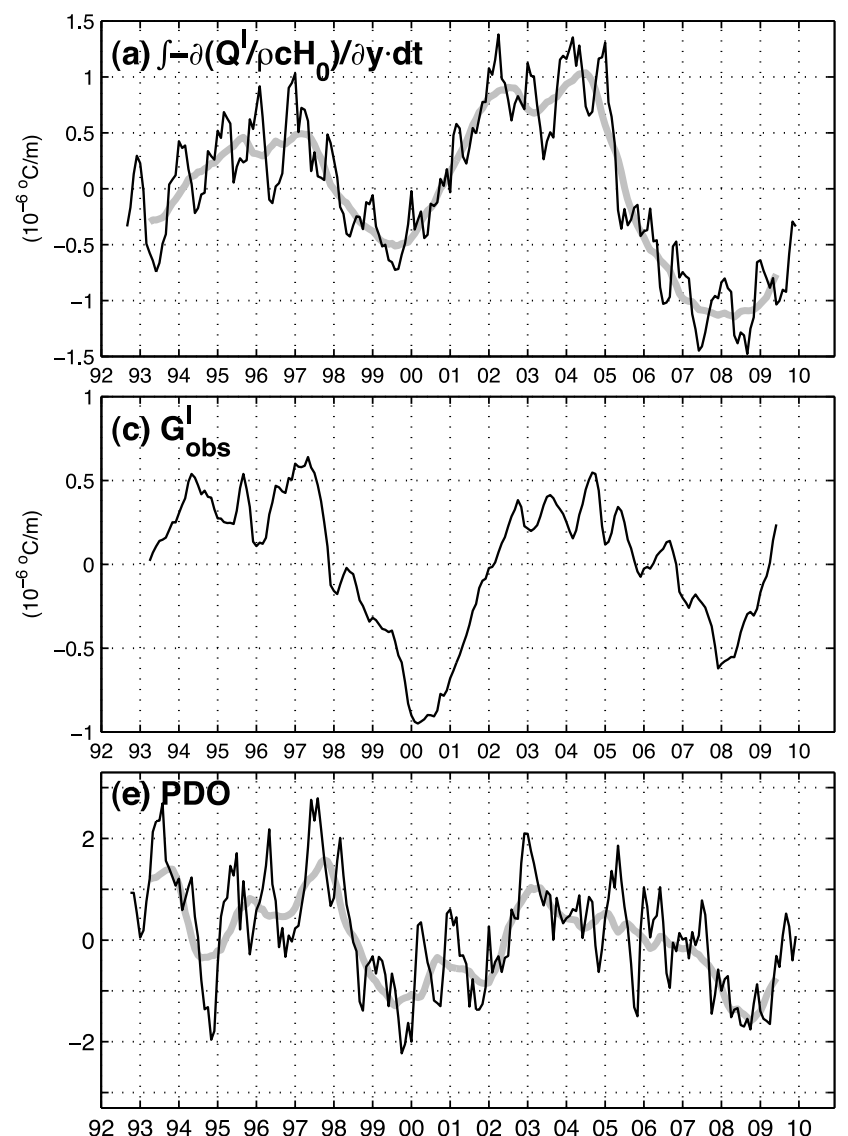

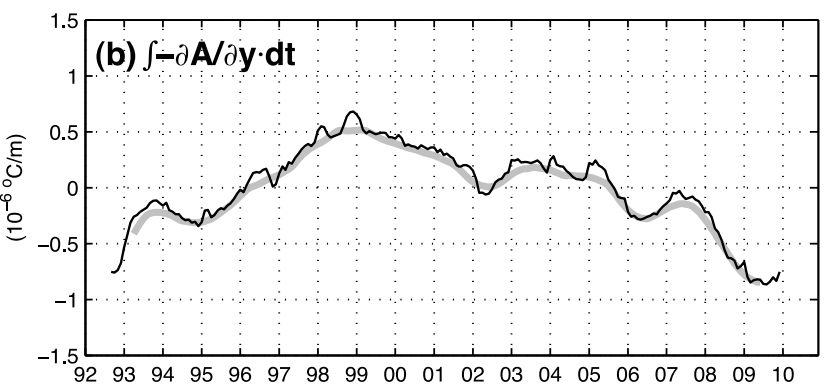

(d) EKE

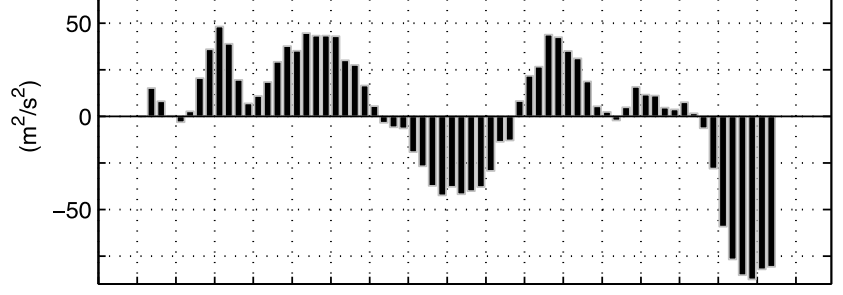

$\begin{array}{lllllllllllllllllll}92 & 93 & 94 & 95 & 96 & 97 & 98 & 99 & 00 & 01 & 02 & 03 & 04 & 05 & 06 & 07 & 08 & 09 & 10\end{array}$

Figure 8. Interannual variation of (a) the differential surface heat flux forcing term, (b) the Ekman flux convergence forcing term, (c) $G_{o b s}^{\prime}$, (d) seasonally averaged EKE time series averaged in the HLCC region as in Figure 3b, and (e) Pacific Decadal Oscillation (PDO) index. Gray thick curves in Figures 8a, 8b, and $8 \mathrm{e}$ and thin black curve in Figure 8c indicate interannual changes after 13 month running mean filter is applied to the original monthly time series.

baroclinic instability of the adjusted HLCC-NEC system to fully grow [Qiu and Chen, 2010].

[20] The low-frequency $G_{o b s}^{\prime}$ variability is significantly correlated with the Pacific Decadal Oscillation (PDO) index shown in Figure 8e [Mantua et al., 1997]. The PDO index, which represents the leading principal component of the large-scale North Pacific SST variability, is mostly positive in 1992 to mid-1998 and mid-2002 to 2007, negative in mid1998 to mid-2002 and after 2008, and its linear correlation coefficient with $G_{o b s}^{\prime}$ reaches 0.73 . The positive and negative PDO phases modulate similarly to the EKE I to IV phases with PDO leading 6 months to 1 year.

[21] The causal relationship between the PDO and HLCC's EKE signals can be understood as follows. As shown schematically in Figure 10, during the positive PDO phase when the Aleutian low-pressure system is strengthened over the midlatitude North Pacific Ocean, upward heat fluxes north of the HLCC are amplified compared to south of the HLCC. This $y$-dependent anomalous surface heat flux forcing intensifies the SST gradient $G^{\prime}$, which in turn enhances the vertical shear between the HLCC and the underlying NEC through the thermal wind balance, equation (2). The increased vertical shear between HLCC and NEC favors stronger baroclinic instability and leads to an elevated EKE

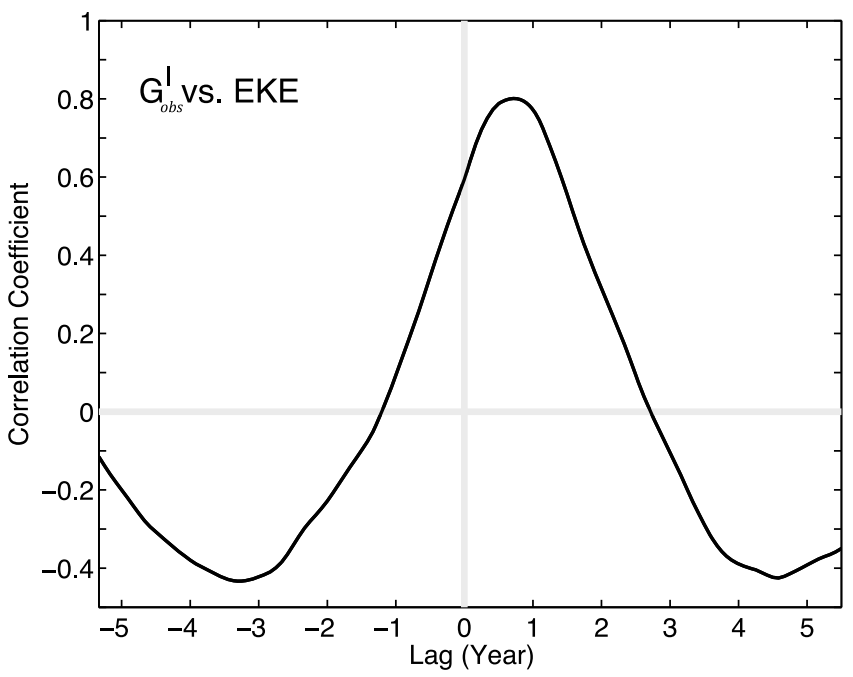

Figure 9. Lagged correlation between the interannually varying EKE time series and the meridional gradient of sea surface temperature $G_{\text {obs }}^{\prime}$ in the HLCC band. 


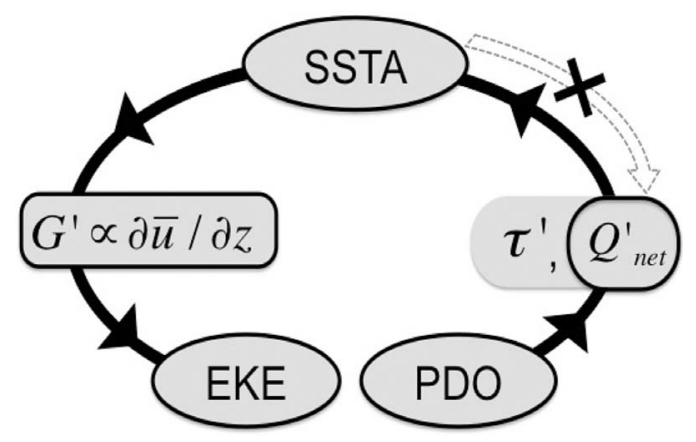

Figure 10. Schematic view of the connection between the HLCC eddy activity and large-scale PDO index. During the positive PDO phase, for example, when the Aleutian lowpressure system is strengthened over the midlatitude North Pacific Ocean, upward heat fluxes north of HLCC are amplified compared to south of the HLCC. This $y$-dependent anomalous surface heat flux forcing intensifies the SST gradient $G^{\prime}$, which in turn enhances the vertical shear between the HLCC and the NEC.

level along the HLCC band. The opposite scenario occurs when the PDO index switches to negative.

\section{Discussion and Conclusions}

[22] Interannual eddy variability in the Hawaiian Lee Counter Current (HLCC) region is investigated in this study using the satellite altimeter sea surface height data of the past 17 years. The eddy kinetic energy (EKE) time series averaged over the HLCC band $\left(17^{\circ} \mathrm{N}-21.7^{\circ} \mathrm{N}, 170^{\circ} \mathrm{E}-160^{\circ} \mathrm{W}\right)$ has strong seasonal and interannual modulations. The prevailing interannual EKE signals show enhanced eddy activities in 1993-1998 and 2002-2006, and subpar eddy activities in 1999-2001 and 2007-2009. The dominant eddy signals in the HLCC band have a time scale of $100 \mathrm{~d}$, and they propagate westward with an average phase speed about $6.8 \mathrm{~cm} / \mathrm{s}$. The HLCC is surface-intensified with a mean zonal velocity of $0.05 \mathrm{~m} / \mathrm{s}$ and it extends vertically down to the $200 \mathrm{~m}$ depth.

[23] Since the major driving force of the time-mean HLCC is the orographically induced wind stress curl resulting from the islands' high mountains, we estimate the local wind stress curl-induced zonal velocity change in the HLCC by assuming the Sverdrup balance, and investigate its relationship with the interannual EKE variability. While exhibiting interannual fluctuations, the zonal HLCC velocity generated by the dipolar wind stress curl forcing in the lee of the Island of Hawaii shows no significant correlation with the observed interannual EKE time series. This result is confirmed with both the QuikSCAT and ECMWF reanalysis wind stress products and hence suggests that the interannual changes in the strength of the HLCC are not governed by the localized wind stress curl forcing.

[24] The second hypothesis tested in this study for the observed interannual EKE variability in the HLCC is the vertical shear of the zonal geostrophic velocity in the HLCCNEC system. To do so, we examined the meridional temperature gradient $(G=-\partial T / \partial y)$ changes along the HLCC band. By comparing $G_{o b s}^{\prime}$ with the forcing terms in the upper ocean heat balance equation, we found the differential surface net heat flux forcing term matches well with the interannually varying EKE signals with a lead of approximately 8-10 months. This result suggests that the differential heat flux forcing plays a dominant role in driving the meridional SST gradients, which in turn changes the HLCC vertical shear and induces the EKE variability through baroclinic instability of different intensities. The forcing mechanism introduced in this study is different from that of the STCC [Qiu and Chen, 2010]. This implies that the eddy variabilities over the two different eastward flows in the same latitudinal band are controlled by the different large-scale forcing fields. Future investigations are needed to address eddy signals induced by Ekman and heat flux forcings in these two regions, and to understand how these eddy signals are controlled by the large-scale climate variability.

[25] The connection between the eddy activity around the Hawaiian Islands and the basin-scale climate variability has been reported in several papers. Mitchum [1995] showed evidence that the intermittent $90 \mathrm{~d}$ oscillations observed at Wake Island with an energy source near the Hawaiian Islands tend to occur about 1.5 years after El Niño events. Chen and Qiu [2010] found that the interannual EKE variations northeast of the Hawaiian Archipelago were well correlated to the PDO index with lags of 10-14 months and pointed to the importance of the Ekman pumping associated with the Aleutian Low activity. Along the HLCC band, we found in this study that $G_{o b s}^{\prime}$ is significantly correlated with the PDO index on the interannual time scale. This positive correlation occurs because the anomalous surface heat flux forcing during the positive phase of the PDO index generates a greater anomalous SST gradient across the HLCC front. This enhanced SST gradient induces a strengthened vertical shear in the zonal geostrophic flow between the surface HLCC and the subsurface NEC, causing strong baroclinic instability and leading to a higher level in the regional EKE field.

[26] Since the surface heat flux and SST interact with each other, it is important to clarify the cause-and-effect relationship between these two variables. For the scenario of the atmosphere forcing the ocean, anomalous surface heat fluxes heat the upper ocean and cause positive SST anomalies. In this case, the correlation between the anomalous heat flux and SST tends to be positive. For the scenario of SST anomalies driving the atmosphere, positive SST anomalies

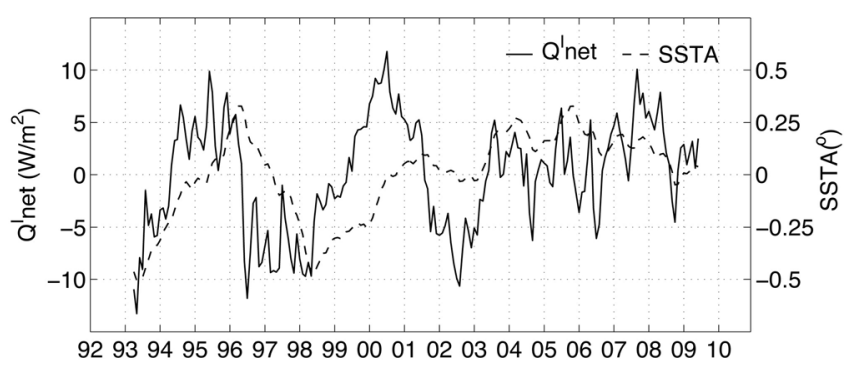

Figure 11. Monthly averaged surface net heat flux anomalies $Q_{\text {net }}^{\prime}$ (solid line) and the sea surface temperature anomalies (dashed line, scale on the right) in the HLCC band. Both the $Q_{n e t}^{\prime}$ and sea surface temperature anomaly (SSTA) time series are smoothed using a 1 year running mean. 
work to increase the surface heat loss from the ocean, hence there exists a negative correlation between the surface heat flux and SST anomalies. Figure 11 shows the monthly average surface heat flux and SST anomalies along the HLCC band. The correlation coefficient between these two time series exceeds 0.5 with the heat flux anomaly leading from a few months to a year. This positive correlation in $\left\langle Q^{\prime}{ }_{n e t}(t) T^{\prime}(t)\right\rangle$ is consistent with our hypothesis that the PDO-related surface heat flux forcing drives the SST changes associated with the HLCC front and leads to the regional EKE variations through the modulating baroclinic instability in the HLCC-NEC system (Figure 10).

[27] Acknowledgments. The altimeter product and surface wind data were provided by the CLS Space Oceanography Division and the Remote Sensing Systems and NASA Ocean Vector Winds Science Team, respectively. We acknowledge support from NOAA through grant NA17RJ1230 for S.Y. and P.H. and NASA's Ocean Surface topography Mission through JPL contract 1207881 for B.Q. This is IPRC publication 822 and SOEST publication 8506 .

\section{References}

Balmaseda, M. A., A. Vidard, and D. L. T. Anderson (2008), The ECMWF ocean analysis system: ORA-S3, Mon. Weather Rev., 136, 3018-3034, doi:10.1175/2008MWR2433.1.

Calil, P. H. R., K. J. Richards, Y. Jia, and R. R. Bidigare (2008), Eddy activity in the lee of the Hawaiian Islands, Deep Sea Res., Part II, 55, 10-13, doi:10.1016/j.dsr2.2008.01.008.

Chelton, D. B., and M. G. Schlax (1996), Global observations of oceanic Rossby waves, Science, 272, 234-238, doi:10.1126/science.272.5259.234.

Chen, S., and B. Qiu (2010), Mesoscale eddies northeast of the Hawaiian archipelago from satellite altimeter observations, J. Geophys. Res., 115, C03016, doi:10.1029/2009JC005698.

Flament, P., S. Kennan, C. Lumpkin, M. Sawyer, and E. Stroup (1998), The ocean, in Atlas of Hawaii, 3rd ed., edited by S. P. Juvik and J. O. Juvik, pp. 82-86, Univ. of Hawaii Press, Honolulu.

Hasunuma, K., and K. Yoshida (1978), Splitting the subtropical gyre in the western North Pacific, J. Oceanogr. Soc. Jpn., 34, 160-172, doi:10.1007/ BF02108654.

Holland, C. L., and G. T. Mitchum (2001), Propagation of Big Island eddies, J. Geophys. Res., 106, 935-944, doi:10.1029/2000JC000231.

Kobashi, F., and H. Kawamura (2002), Seasonal variation and instability nature of the North Pacific Subtropical Countercurrent and the Hawaiian Lee Countercurrent, J. Geophys. Res., 107(C11), 3185, doi:10.1029/ 2001JC001225.

Kobashi, F., H. Mitsudera, and S. P. Xie (2006), Three subtropical fronts in the North Pacific: Observational evidence for mode water-induced subsurface frontogenesis, J. Geophys. Res., 111, C09033, doi:10.1029/ 2006JC003479.

Mantua, N. J., S. R. Hare, Y. Zhang, J. M. Wallace, and R. C. Francis (1997), A Pacific interdecadal climate oscillation with impacts on salmon production, Bull. Am. Meteorol. Soc., 78, 1069-1079, doi:10.1175/15200477(1997)078<1069:APICOW>2.0.CO;2.

Mitchum, G. T. (1995), The source of the 90-day oscillations at Wake Island, J. Geophys. Res., 100, 2459-2475, doi:10.1029/94JC02923.

Nakamura, H., and A. S. Kazmin (2003), Decadal changes in the North Pacific oceanic frontal zones as revealed in ship and satellite observations, J. Geophys. Res., 108(C3), 3078, doi:10.1029/1999JC000085.

Niiler, P. P., N. A. Maximenko, and J. C. McWilliams (2003), Dynamically balanced absolute sea level of the global ocean derived from near-surface velocity observations, Geophys. Res. Lett., 30(22), 2164, doi:10.1029/ 2003 GL018628.

Qiu, B., and S. Chen (2010), Interannual variability of the North Pacific Subtropical Countercurrent and its associated mesoscale eddy field, J. Phys. Oceanogr., 40, 213-225, doi:10.1175/2009JPO4285.1.

Qiu, B., and T. Durland (2002), Interaction between an island and the ventilated thermocline: Implication for the Hawaiian Lee Countercurrent, J. Phys. Oceanogr., 32, 3408-3426, doi:10.1175/1520-0485(2002) $032<3408$ :IBAIAT $>2.0 . \mathrm{CO} ; 2$.

Qiu, B., D. Koh, C. Lumpkin, and P. Flament (1997), Existence and formation mechanism of the North Hawaiian Ridge Current, J. Phys. Oceanogr., 27, 431-444, doi:10.1175/1520-0485(1997)027<0431:EAFMOT>2.0.CO;2.

Reynolds, R. W., N. A. Rayner, T. M. Smith, D. C. Stokes, and W. Wang (2002), An improved in situ and satellite SST analysis for climate, J. Clim., 15, 1609-1625, doi:10.1175/1520-0442(2002)015<1609: AIISAS $>2.0 . \mathrm{CO} ; 2$.

Sakamoto, T. T., A. Sumi, S. Emori, T. Nishimura, H. Hasumi, T. Suzuki, and M. Kimoto (2004), Far-reaching effects of the Hawaiian Islands in the CCSR/NIES/FRCGC high-resolution climate model, Geophys. Res. Lett., 31, L17212, doi:10.1029/2004GL020907.

Sasaki, H., S. P. Xie, B. Taguchi, M. Nonaka, and Y. Masumoto (2010), Seasonal variations of the Hawaiian Lee Countercurrent induced by the meridional migration of the Trade Winds, Ocean Dyn., 60, 705-715, doi:10.1007/s10236-009-0258-6.

Sasaki, N., and M. Nonaka (2006), Far-reaching Hawaiian Lee Countercurrent driven by wind-stress curl induced by warm SST band along the current, Geophys. Res. Lett., 33, L13602, doi:10.1029/2006GL026540.

Uda, M., and K. Hasunuma (1969), The eastward subtropical countercurrent in the western North Pacific Ocean, J. Oceanogr. Soc. Jpn., 25, 201-210.

Xie, S. P., W. T. Liu, and M. Nonaka (2001), Far-reaching effects of the Hawaiian Islands on the Pacific Ocean-atmosphere system, Science, 292, 2057-2060, doi:10.1126/science.1059781.

Yoshida, S., B. Qiu, and P. Hacker (2010), Wind-generated eddy characteristics in the lee of the island of Hawaii, J. Geophys. Res., 115, C03019, doi:10.1029/2009JC005417.

P. Hacker, International Pacific Research Center, University of Hawai'i at Mānoa, 1680 East-West Rd., Honolulu, HI 96822, USA.

B. Qiu, Department of Oceanography, University of Hawai'i at Mānoa, 1000 Pope Rd., Honolulu, HI 96822, USA.

S. Yoshida, Department of Physical Oceanography, Woods Hole Oceanographic Institution, 266 Woods Hole Rd., MS 21, Woods Hole, MA 02543, USA. (syoshida@whoi.edu) 